\title{
Pharmaceutical Waste Management in Pharmacies at the Primary Level of Health Care in Serbia - Situation Analysis
}

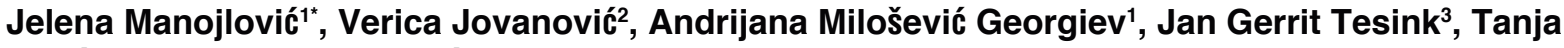 \\ Arsić $^{4}$, Valentina Marinković ${ }^{1}$ \\ ${ }^{1}$ Department of Social Pharmacy and Pharmaceutical Legislation, University of Belgrade Faculty of Pharmacy, Belgrade, Serbia \\ ${ }^{2}$ Centre for disease control, Institute of Public Health "Dr Milan Jovanovic Batut", Belgrade, Serbia \\ ${ }^{3} \mathrm{TA}$ HCW project units, COWI, Denmark \\ ${ }^{4}$ Department of pharmacy, Pharmacy Niš, Niš, Serbia
}

\begin{abstract}
Background: Pharmaceutical products can become a potential source of poisoning. The improper disposal of unused medicines is a growing problem throughout the world, with a manifold effect on the cost of health care, public health and the environment. The objectives of this research are the overview of current situation of pharmaceutical waste management in the pharmacy sector in the Republic of Serbia, attitudes and knowledge of pharmacists on the matter and the measures they should undertake in order to make the general public aware of the significance of proper disposal of medications. Methods: The research was conducted as a cross-sectional study on entire population of state pharmacies at the primary health care level in the Republic of Serbia, in March 2013. Primary data were collected by filling in a 14 questions questionnaire that was specially designed for this research. Results: The questionnaire was completed by 683 (34 healthcare institutions - pharmacy) pharmacies. According to the data obtained, $76.5 \%$ of pharmacies collect expired medicines that people bring there in order to get them put away, while $23.5 \%$ pharmacies assert that they do not collect pharmaceutical waste from households at all. Conclusion: The pharmacies have not started to implement their legal obligation of collecting pharmaceutical waste from the citizens yet, at least not in the full range. The development and practical implementation of adequate procedures and facilities for the disposal of this type of waste represents the key step towards the decrease of pharmaceutical waste in the environment.
\end{abstract}

Key words: pharmaceutical waste, environment, unused medicines, expired medicines, pharmacy, waste management, waste law.

\section{INTRODUCTION}

Pharmaceutical products were not recognised as environmental pollutants until the 1980s. The pollution that results from the inadequate disposal of unused pharmaceutical products is very complex since their structure consists of thousands of different active molecules that are parts of different therapeutical groups with different physicochemical properties and chemical structures. They behave differently in the environment and have different stability. ${ }^{1}$ Since these components have been detected in wastewaters, in the soil and in drinking water, they have become even bigger problem. ${ }^{2}$ Pharmaceutical products have been used and produced in large amounts nowadays. Their diversity and the development of innovated medicaments are on the constant rise. The household medicine supplies can vary in different countries, but they can all become a potential source of poisoning, most often for children, and can also cause reactions like confusion, especially with elderly persons. ${ }^{3}$ According to the 2008 report of the American Association of Poison Control Centers (AAPCC), the cause of $18.6 \%$ of child poisoning were acute medicine poisonings. When found in water flows, even in traces, Etinilestradiol, which is an active component of most oral contraceptives, jeopardizes sexual development of fish and increases their feminization. ${ }^{3}$ Pharmaceuti-
Submission Date: 09.12 .2014 Revision Date : :23.12.2014 Accepted Date : : 19.01.2015 DOI: 10.5530/ijper.49.2.5 Correspondence Address Dr. Jelena Manojlović, Department of Social Pharmacy and Pharmaceutical Legislation,

University of Belgrade, Faculty of Pharmacy, Vojvode Stepe 450, 11000 Belgrade Phoneno:+381113951212 E-mail:jmanojlovic@pharmacy.bg.ac.rs

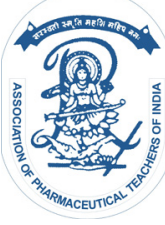

www.ijper.org 
cal products get into the environment in two main ways. Firstly, as a result of their use in treatment of patients, they enter the environment with wastewaters after the excretion from the body. After the use, a significant part of a pharmaceutical product runs through the body unmetabolised. Secondly, there is a disposal of the expired medicines or the medicines unused for some other reason. They are thrown into the toilet, into the communal waste or onto landfills and dumpsites. ${ }^{1}$ There is usually a recommendation on the packaging's of medications that the adequate disposal of these products is their return to the pharmacy. Unfortunately, the pharmacists are not fully aware yet that they should inform the customers what they should do if they do not use all the medicines.

According to the current regulation in the Republic of Serbia, the pharmacies have the obligation of collecting the unused medicines from the citizens. That is a significant part of the pharmaceutical waste for which health facility, i.e. the pharmacy that collects it, is responsible for. However, many sorts of waste come from pharmacies themselves, mostly for the following reasons

- Pharmaceutical products, medicines and chemicals that are unused and thrown away

- Expired medicines

- The medicines that became unusable due to their inadequate storage and handling

- The medicines that have to be disposed for some other reason . ${ }^{4}$

Inadequate disposal of unused medicines is becoming a growing problem in the whole world. It influences the cost of health protection and becomes a risk for public health and for the environment in many ways. The unused medicines are both the ones prescribed and unprescribed by a recipe, but unused for some reason. Actually, the reasons can be the oversupply in the market, changes in therapies, mistakes made in prescribing or in supplying medicines, unwanted or allergic reactions, the improvement of health condition or the death of a patient. ${ }^{5}$

There is a growing amount of evidence that the chemicals imitating natural hormones (endocrine disruptors) cause an identical response or block the natural hormones, i.e. they have an alarming effect on critical stages of development in the foetus and newborn. The book Stolen Future, documents the research of Theo Colburn, the pharmacist who identified this phenomenon in populations of wild animals. ${ }^{6}$

In the past, the largest part of pharmaceutical waste was generated due to the expiration of medicines. The development of reverse distribution by the pharmaceu- tical companies allowed the medicines to be returned as products. ${ }^{6}$

The aims of this paper are

- Displaying current status of the pharmaceutical waste management in the pharmacy sector in Serbia.

- The attitudes and knowledge of pharmacists on the management of pharmaceutical waste.

- The measures that should be undertaken in order to introduce the general public with the significance of the adequate disposal of unused medicines.

\section{MATERIAL AND METHODS}

The research has been conducted as a cross-sectional study on entire population of state pharmacies at the primary health care level in Serbia, in March 2013.

The target population of the research was state pharmacy sector at the primary level of health care in the Republic of Serbia. The direct participants in the research were the representatives of the pharmacies, the persons appointed and responsible for waste management. The only criterion was that the pharmacies are state-owned.

The primary data were collected through a 14 questions questionnaire that was specially designed for this research Table 1 . The questions were related to the role of pharmacy staff concerning the waste separation and its disposal. They were asked how well they are introduced with waste management regulations, with taking over the unused medicines from the citizens, and with the financing of the adequate waste treatment. The question of the necessity of informing pharmacists and pharmacy technicians about the technical recommendations regarding the treatment of pharmaceutical waste in the pharmacies was also imposed. The questionnaire was distributed by email to the persons responsible for waste management in the pharmacies

It was sent to 716 pharmacies (35 healthcare institutions - pharmacy), while 683 (34 healthcare institutions - pharmacy) of them responded by filing them in. The

Table 1: Groups of questions within the questionnaire specially designed

\begin{tabular}{|c|c|}
\hline Section & $\begin{array}{c}\text { Number of } \\
\text { questions }\end{array}$ \\
\hline $\begin{array}{c}\text { Behaviour of pharmacists when } \\
\text { generating pharmaceutical waste in } \\
\text { pharmacies }\end{array}$ & 5 \\
\hline $\begin{array}{c}\text { Behaviour of pharmacists when collecting } \\
\text { the pharmaceutical waste from citizens }\end{array}$ & 4 \\
\hline $\begin{array}{c}\text { Attitudes of pharmacists regarding } \\
\text { pharmaceutical waste management, } \\
\text { according to the citizens' opinion }\end{array}$ & 5 \\
\hline
\end{tabular}


list of pharmacies was made in the accordance of the Regulation of the health institutions network plan of the Ministry of Health which states that there are 716 independent (pharmacy) healthcare institutions in the Republic of Serbia.

The collected data have been put into the database and coded. Statistic program SPSS (version 18.0, SPSS Inc) has been used for the analysis. Along with the descriptive analysis, Pearson's $\chi^{2}$ - test, Pearson's correlation/ Spearman's correlation was used for the examining the correlation between some questions.

The Ethics Committee of the Faculty of Pharmacy in Belgrade gave their approval for conducting this research.

\section{RESULTS}

The questionnaire has been completed by a total of 34 health care institutions, i.e. pharmacies. The results show that $76.5 \%$ of pharmacies collect expired medicines that people bring there for the disposal.

The whole amount of the waste generated in pharmacies is being classified in $76.5 \%$ of the pharmacies, while the partial classification is registered in $14.7 \%$ of them. Being asked about the management of the expired medicines, the majority of the pharmacists $(79.4 \%)$ answered they store and keep them until they can be handed over to the appointed person, while only $8.8 \%$ store and export the expired medicines once a year. Over two thirds of respondents $(70.6 \%)$ declared that

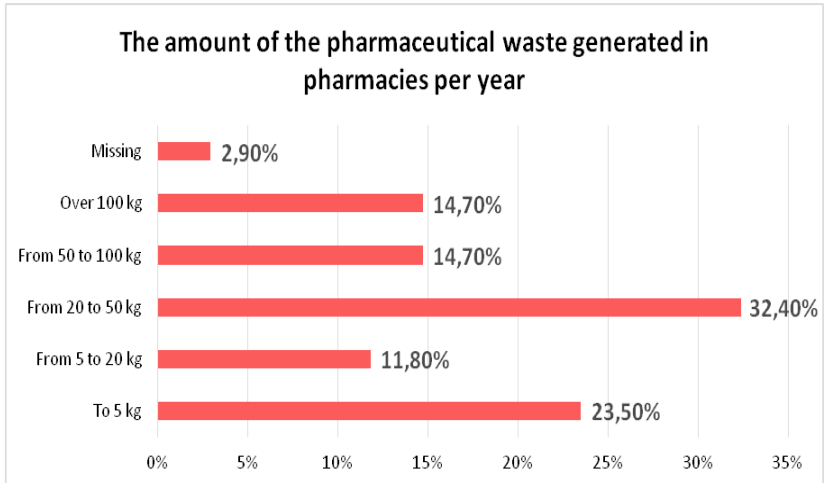

Graphic 1. The amount of the pharmaceutical waste generated in pharmacies per year they do not understand the regulation on the pharmaceutical waste, while $97.1 \%$ say they could use especially designed manual for pharmaceutical waste management. Such instructions (Manual for pharmaceutical waste management) was developed by the TA-HCW Project ("Technical Assistance for the Treatment of Healthcare Waste in Serbia") after the completion of the study. Almost one third of the pharmacies collect between 20 and 50 $\mathrm{kg}$ of pharmaceutical waste a year. On the other hand, approximately the same number of pharmacies collects less than $5 \mathrm{~kg}$ of pharmaceutical waste a year. Graphic 1 shows the distribution of pharmacies regarding the amount of the collected pharmaceutical waste per year.

Pharmacists do not recognize collecting pharmaceutical waste from the citizens as a new pharmaceutical service that could be implemented, but as an inseparable part of the daily routine in almost a third of the pharmacies included in this research (32.4\%). However, $23.5 \%$ of the pharmacies declare they do not collect the pharmaceutical waste from the households, i.e. expired medicines, leftovers due to the change or the termination of therapy, etc., at all. In line with the Law on waste management, almost all the pharmacies $(97.1 \%)$ have the appointed person who is responsible for waste management. However, only $61.8 \%$ of the pharmacists declare that there is a prominent notice in their pharmacy about the procedure of collecting pharmaceutical waste from the citizens although this is a requirement of the same law. $38.2 \%$ of the pharmacies do not display such notice.

Table 2 shows how the respondents answered whether they finance the treatment of the pharmaceutical waste collected from the citizens from their own resources, and whether they find that wholesale companies should be an integral part of the management of this kind of waste.

One of the questions in the questionnaire referred to the attitudes of the pharmacists about the main activities in the management of pharmaceutical waste collected from the citizens. The attitudes of pharmacists regarding the obligations to takeover, classify, dispose and treat the pharmaceutical waste were examined. They were also asked about putting the red containers

\section{Table 2: The attitudes of the pharmacists regarding the collection of pharmaceutical waste from citizens}

\begin{tabular}{|c|c|c|c|c|c|c|}
\hline \multirow{2}{*}{ Question } & \multicolumn{3}{|c|}{ Frequency } & \multicolumn{3}{|c|}{ Percentage (\%) } \\
\hline & yes & no & No answer & yes & no & No answer \\
\hline $\begin{array}{c}\text { Does your institution finances the } \\
\text { treatment of pharmaceutical waste } \\
\text { collected from the citizens from its own } \\
\text { resources? }\end{array}$ & 19 & 13 & 2 & 55.9 & 38.2 & 5.9 \\
\hline $\begin{array}{l}\text { Do you think the wholesale companies } \\
\text { should take part in collecting expired } \\
\text { medicines from the citizens? }\end{array}$ & 25 & 7 & 2 & 73.5 & 20.6 & 5.9 \\
\hline
\end{tabular}


Table 3: The attitudes of the pharmacists regarding the management of the pharmaceutical waste collected

\begin{tabular}{|c|c|c|c|c|c|}
\hline Activity & wholesale & pharmacy & state & operator & Without answer \\
\hline $\begin{array}{c}\text { Taking over } \\
\text { pharmaceutical } \\
\text { waste }\end{array}$ & $2.9 \%$ & $67.6 \%$ & $11.8 \%$ & $5.9 \%$ & $11.8 \%$ \\
\hline $\begin{array}{c}\text { Classification of } \\
\text { pharmaceutical } \\
\text { waste }\end{array}$ & 1 & $52.9 \%$ & $11.7 \%$ & $20.6 \%$ & $14.7 \%$ \\
\hline $\begin{array}{c}\text { Placing waste } \\
\text { containers in } \\
\text { pharmacies }\end{array}$ & $11.8 \%$ & $29.4 \%$ & $29.4 \%$ & $17.6 \%$ & $11.8 \%$ \\
\hline $\begin{array}{c}\text { Placing and } \\
\text { replacement of red } \\
\text { bags }\end{array}$ & $8.8 \%$ & $32.3 \%$ & $20.5 \%$ & $23.5 \%$ & $14.7 \%$ \\
\hline $\begin{array}{c}\text { Taking over } \\
\text { pharmaceutical } \\
\text { waste from } \\
\text { pharmacies }\end{array}$ & $14.7 \%$ & $/$ & $20.6 \%$ & $50 \%$ & $14.7 \%$ \\
\hline $\begin{array}{c}\text { Disposal of } \\
\text { pharmaceutical } \\
\text { waste }\end{array}$ & $11.8 \%$ & $5.9 \%$ & $23.5 \%$ & $44.1 \%$ & $14.7 \%$ \\
\hline $\begin{array}{c}\text { Treatment of } \\
\text { pharmaceutical } \\
\text { waste }\end{array}$ & $8.8 \%$ & $2.9 \%$ & $23.5 \%$ & $50 \%$ & $14.7 \%$ \\
\hline
\end{tabular}

at pharmacies and about the replacement of red bags, which are mandatory requirements proscribed by the national regulations for the collection of pharmaceutical waste. The results are shown in Table 3.

Statistic test proved there is no statistic significance between the district where a pharmacy is and the activities related to the process of collecting pharmaceutical waste from the citizens $\left(\chi^{2}=4.28, \mathrm{p}=0.232\right)$. Also, there are no significant differences regarding the understanding of the law regulation on the waste management $\left(\chi^{2}=6.78, p=0.079\right)$. However, there is a statistically significant discrepancy in the attitudes of the pharmacists in relation to the statement that wholesales should be the part of the "chain" in collecting the expired medicines from the citizens $(\mathrm{p}=0.006)$.

\section{DISCUSSION}

The treatment of pharmaceutical waste varies in different countries of the world. In some of them, like Egypt, it has been accepted that unused medicines should be returned to pharmacies and reissued to the patients. ${ }^{5}$ However, such rationalization of medicines is considered ethically unacceptable because of lack of safety and the inability to monitor the process of storing medicines while they are in the possession of users. There is a proposal in the Netherlands to attach an indicator strip on each medicine packaging that will change color when the medicine is inadequately stored. That would ensure greater reliability in re-issuing unused medications which are still unexpired.

Different pilot projects have been conducted in Canada. Their aim is to determine whether the adjustment of the amount of medicine issued to every patient could result in decreasing health care costs and the decrease of the unused medicines amount, i.e. the amount of the pharmaceutical waste. ${ }^{5}$ The problem with this proposal in Serbia is associated with the national legislation which does not permit the issuance or sale of individual medicines, i.e. the medicines out of their original packaging. Sometimes the amount of medicines in the boxes exceeds the need for specific therapy to a large extent, which leads to the growth of the amount of unused medicines. However, there is one more possible solution for this problem - to include manufacturers and get them start the production of packages with different number of medicines.

Prescribers of medicines in New Zealand have a legal license to prescribe three months therapy for chronic diseases, and even 6 months for oral contraception. This way of prescribing medicines resulted in a very low percentage of unused ones that are being returned to pharmacies. The studies in Great Britain show that only $22 \%$ of unused medicines are being brought back to pharmacies. In the United States, that percentage is also very low, $23 \%$. However, it is a significantly higher value than the one reached in the study 10 years ago when it was $2 \%$. A study conducted in New Zealand shows that 
the percentage of the medicines returned to pharmacies is between 13 and $24 \%{ }^{3}$

There are 314 independent pharmacies in Denmark and the amount of pharmaceutical waste generated is 120 grams per person per year. Pharmacies are required to collect pharmaceutical waste from households. The town is responsible for the procurement of packaging, collection and treatment of pharmaceutical waste. The collected pharmaceutical waste is taken to the hazardous waste storages before transporting to a facility for treatment. The amount of pharmaceutical waste collected through pharmacies is about 1100 tons per year, or 70 grams per person per year. ${ }^{7}$

Such low percentage of responsible citizens in developed countries, where the education of the population is already at high level, shows that it would take a lot of effort in Serbia to raise awareness about the harmful effects of the improper management of pharmaceutical waste on one hand and to get the first results of the campaigns undertaken on the other.

Some researches show that when it comes to the inadequate pharmaceutical waste management, examinees are mostly feared of the infectious diseases that could develop under these conditions but also of the increased volume of allergic reactions. ${ }^{7}$ Such facts should also be considered in the countries where this kind of researches have not been undertaken yet because they could motivate citizens to practice safe and adequate pharmaceutical waste management. ${ }^{8}$

Available data provide consistent indications that the facilities for pharmaceutical waste destruction are often located disproportionately in areas with smaller populations or in places housing ethnic minorities. ${ }^{9}$ There are numerous dumps and abandoned industrial zones in Serbia that could be adjusted for the facilities for pharmaceutical waste destruction. This would save health care system financial resources to a great extent.

Based on the analysed data it can be concluded that the pharmacies have not started to accept the legal obligation of collecting pharmaceutical waste from the citizens yet. They mostly undertake incomplete activities that vary among pharmacies since the respondents stated that the national legislation is not accessible, precise or clear enough for them.

Most of the pharmacists questioned consider that the financial support in the pharmaceutical waste management is the biggest obstacle for the proper treatment of pharmaceutical waste. The development and implementation of adequate procedures in practice, as well as the development of the facilities for the destruction of this type of waste is the key step towards reducing the amount of pharmaceutical waste in the environment.
Targeted campaigns must be executed in order to increase awareness of both the experts and the general public.

According to the acquired results, the measures for the improvement of the pharmaceutical waste management have been determined. The proposed measures are:

- Adjustment of patients' therapies, thus regulating the amount of the issued medicines. This is the most demanding measure, since it implies changing the behaviour and the activities of pharmacists and of the doctors who prescribe a therapy;

- Public health service activities aimed at general public, which would be conducted through pharmacies and through other forms of health promotion in public places;

- Inclusion of students of pharmacy in promoting activities and in the education of general public

- Introduction of students at high schools and faculties of medicine profile with mandatory training on medical waste in order to educate future health workers in time.

\section{CONCLUSION}

*Pharmacies in the Republic of Serbia are not fully implementing the legal framework concerning pharmaceutical waste management generated by citizens.

* They mostly undertake incomplete activities concerning collection, segregation and proper disposal of this waste stream.

* There is a different practice concerning pharmaceutical waste management collected from citizens implemented by pharmacies.

* Attitudes of pharmacists concerning proper pharmaceutical waste management are different in different pharmacies and different regions.

As very important reasons not to implement proper pharmaceutical waste management with pharmaceutical's from collected medicines from household's pharmacist are listing that current legal framework in Serbia is not enough clear for professional's in this field, and there is no financial resources to cover generated expenditure for proper disposal of collected pharmaceutical waste from citizens. Once, when pharmacies collect the pharmaceutical waste from third party than those outlets are becoming the owners of waste, with all obligation concerning proper pharmaceutical waste management. The only method to do proper disposal of pharmaceutical waste from citizens is export abroad which generates high costs for pharmacies. Republic Health Insurance Fund does not covering those expenditures. 
Proper pharmaceutical waste management concerning pharmaceutical waste generated in the pharmacies is obligatory task of all pharmacies and it goes in line with Regulation on medical waste management and Waste Management Law.

\section{CONFLICT OF INTEREST}

There is no conflict of interests concerning data presentation and analysis by the authors.

\section{REFERENCES}

1. Bound PJ, Voulvoulis N. Household Disposal of Pharmaceuticals as a Pathway for Aquatic Contamination in the United Kingdom. Environ Health Perspect 2005; 113(12): 1705-11. doi:10.1289/ehp.8315 available via http:// dx.doi.org/ [Online 9 August 2005]

2. White RJ, Belmont AM, Metcalfe DC. Pharmaceutical Compounds in Wastewater: Wetland Treatment as a Potential Solution. The Scientific World Journal 2006; 6: 1731-6.

3. Braund R, Peake MB, Shieffelbien L. Disposal practices for unused medications in New Zealand. Environment International 2009; 35(6): 952-5.

4. Law on Waste Management. Official Gazette RS 36/2009 and 88/2010.

5. Samaa ZI, Heba MM, El-Haddad ZI. Analysis of medications returned to community pharmacies in Alexandria. Egypt. Life Sci. J. 2012; 9(2): 746-51.

\section{ACKNOWLEDGMENT}

The research was conducted as part of an integral and interdisciplinary scientific research project financed by the Ministry of Education and Science of the Republic of Serbia (project No. 175036). The authors would like to thank Bajat Snežana for her support and advice.
6. Smith AC. Managing Pharmaceutical Waste-what pharmacists should know. Journal of the Pharmacy Society of Wisconsin. 2002 Nov/Dec; 17-22.

7. Mols A. Management of pharmaceutical waste in the European Union. Data from the project Technical Assistance for the Treatment of Healthcare Waste in Serbia. 2013 February; 15-17.

8. Martuzzi M, Mitis F, Forastiere F. Inequalities, inequities, environmental justice in waste management and health. European Journal of Public Health 2010; 20(1): 21-6.

9. Sessa A, Di Giuseppe G, Marinelli P, Angelillo FI. Public concerns and behaviours towards solid waste management in Italy. European Journal of Public Health 2009; 20(6): 631-3. 